\title{
Single-Cell RNA-Sequencing Identifies Activation of TP53 and STAT1 Pathways in Human T Lymphocyte Subpopulations in Response to Ex Vivo Radiation Exposure
}

\author{
Maria Moreno-Villanueva ${ }^{1,2}$, Ye Zhang ${ }^{3}$, Alan Feiveson ${ }^{1}$, Brandon Mistretta ${ }^{4} \oplus$, \\ Yinghong Pan ${ }^{4}$, Sujash Chatterjee ${ }^{4}$, Winston $\mathrm{Wu}^{5}$, Ryan Clanton ${ }^{1} \mathbb{D}$, Mayra Nelman-Gonzalez ${ }^{6}$, \\ Stephanie Krieger ${ }^{6}$, Preethi Gunaratne ${ }^{4}$, Brian Crucian ${ }^{1}$ and Honglu $\mathrm{Wu}^{1 \text {,** }}$ \\ 1 NASA Johnson Space Center, Houston, TX 77058, USA; \\ maria.moreno-villanueva@uni-konstanz.de (M.M.-V.); alan.h.feiveson@nasa.gov (A.F.); \\ rc1025@tamu.edu (R.C.); brian.crucian-1@nasa.gov (B.C.) \\ 2 Human Performance Research Center, University of Konstanz, 78457 Konstanz, Germany \\ 3 NASA Kennedy Space Center, Cape Canaveral, FL 32899, USA; ye.zhang-1@nasa.gov \\ 4 Department of Biology and Biochemistry, University of Houston, Houston, TX 77204, USA; \\ branmistretta@gmail.com (B.M.); ypan6@central.uh.edu (Y.P.); ssc308@nyu.edu (S.C.); \\ phgunara@central.uh.edu (P.G.) \\ 5 Department of Computer Science, Johns Hopkins University, Baltimore, MD 21218, USA; wwu37@jhu.edu \\ 6 KBRWyle, Houston, TX 77058, USA; mayra.a.nelman@nasa.gov (M.N.-G.); \\ stephanie.s.krieger@nasa.gov (S.K.) \\ * Correspondence: honglu.wu-1@nasa.gov
}

Received: 1 April 2019; Accepted: 6 May 2019; Published: 10 May 2019

check for updates

\begin{abstract}
Detrimental health consequences from exposure to space radiation are a major concern for long-duration human exploration missions to the Moon or Mars. Cellular responses to radiation are expected to be heterogeneous for space radiation exposure, where only high-energy protons and other particles traverse a fraction of the cells. Therefore, assessing DNA damage and DNA damage response in individual cells is crucial in understanding the mechanisms by which cells respond to different particle types and energies in space. In this project, we identified a cell-specific signature for radiation response by using single-cell transcriptomics of human lymphocyte subpopulations. We investigated gene expression in individual human $T$ lymphocytes $3 \mathrm{~h}$ after ex vivo exposure to 2-Gy gamma rays while using the single-cell sequencing technique (10X Genomics). In the process, RNA was isolated from $\sim 700$ irradiated and $\sim 700$ non-irradiated control cells, and then sequenced with $\sim 50 \mathrm{k}$ reads/cell. RNA in each of the cells was distinctively barcoded prior to extraction to allow for quantification for individual cells. Principal component and clustering analysis of the unique molecular identifier (UMI) counts classified the cells into three groups or sub-types, which correspond to $\mathrm{CD} 4+$, naïve, and $\mathrm{CD} 8+/ \mathrm{NK}$ cells. Gene expression changes after radiation exposure were evaluated using negative binomial regression. On average, $B B C 3, P C N A$, and other TP53 related genes that are known to respond to radiation in human $\mathrm{T}$ cells showed increased activation. While most of the TP53 responsive genes were upregulated in all groups of cells, the expressions of IRF1, STAT1, and $B A T F$ were only upregulated in the CD4+ and naïve groups, but were unchanged in the CD8+/NK group, which suggests that the interferon-gamma pathway does not respond to radiation in $\mathrm{CD} 8+/ \mathrm{NK}$ cells. Thus, single-cell RNA sequencing technique was useful for simultaneously identifying the expression of a set of genes in individual cells and T lymphocyte subpopulation after gamma radiation exposure. The degree of dependence of UMI counts between pairs of upregulated genes was also evaluated to construct a similarity matrix for cluster analysis. The cluster analysis identified a group of TP53-responsive genes and a group of genes that are involved in the interferon gamma pathway,
\end{abstract}


which demonstrate the potential of this method for identifying previously unknown groups of genes with similar expression patterns.

Keywords: single-cell RNA-sequencing; radiation; human T cells

\section{Introduction}

In space, astronauts are constantly exposed to cosmic radiation that consists of energetic charged particles [1]. The cellular effects of space radiation exposure, particularly at the molecular level, have thus far been assessed mostly in pools of cells that have been irradiated with a single particle type [2]. However, in the space environment, only a small fraction of the cells would be traversed by particles at a given time. In such an environment, the cells may experience severe radiation damage, possibly leading to chromosomal aberrations or cell death [3,4]. Additionally, damage can be induced in bystander cells through non-targeted effect mechanisms [5,6]. Thus, it is necessary to investigate the cellular responses to space radiation exposure in individual cells in order to accurately assess the associated health risks. Radiation-induced gene expression has been assessed in populations of cultured cells or in animal tissues, while chromosome aberrations and DNA strand breaks can be analyzed in individual cells [7-10]. The single-cell RNA sequencing technique (scRNA-seq) can reveal complex regulatory relationships between genes [11], allowing us to identify pathways of distinct cell subsets in response to radiation. Scientists have been improving high throughput microfluidic techniques for the isolation of single cells for almost a decade [12]. Advancements in technology have increased the accessibility and decreased costs. Currently, single cells can be captured in an oil droplet containing one hydrogel bead (gel bead) that is labeled with unique barcoded oligonucleotides that tag individual cells [13]. scRNA-seq has been applied in multiple research fields, such as in cancer biology for exploring tumor cell heterogeneity, in immunology for identifying new T cell receptors, or in neuroscience for investigating neural cell diversity [14-16].

Although scRNA-seq analysis will eventually be intended for charged particles or space applications, we report the results of scRNA-seq analysis for human lymphocytes after exposure ex vivo to Cs-137 gamma rays here. Several studies reported quantitative and functional complex interactions between the different components of the immune system in response to radiation. Some of the radiation-induced late effects are related to the immune and inflammatory pathways. Furthermore, low-dose radiation exposure due to environmental sources, cosmic travel, or medical diagnostic techniques is becoming a major epidemiological concern world-wide and there is a need for understanding the mechanisms behind low-dose radiation and the potential long-term health consequences [17]. Studies regarding gene expression in human lymphocytes after gamma or X-rays irradiation have been mostly carried out in the context of developing biodosimetry techniques [18-20]. However, to our knowledge, no scRNA-seq studies of human blood cells in response to radiation exposure have been reported. 


\section{Results}

\subsection{Verification and Identification of Isolated Cell Subpopulations by FACS}

\subsubsection{Cell Types}

The viability of both irradiated and control cells, as determined by Guava ViaCount technology, was greater than $90 \%$. Although we intended to only isolate T cells, some natural killer (NK) cells were included in the cell population studied. Using flow cytometry, we found that approximately $7.2 \%$ of the cells studied were NK cells (CD16+) (Figure 1A). At the same time, we found that approximately $89.6 \%$ of the cells were T-cells (CD3+) (Figure 1B). Of the CD3 positive cells, approximately $56.4 \%$ were CD4+ (CD8-), while 29.7\% were CD8+ (CD4-). A fairly small fraction of cells (13.1\%) were double negative in the staining, while almost none of the cells $(0.8 \%)$ were double positive (Figure $1 \mathrm{C})$.
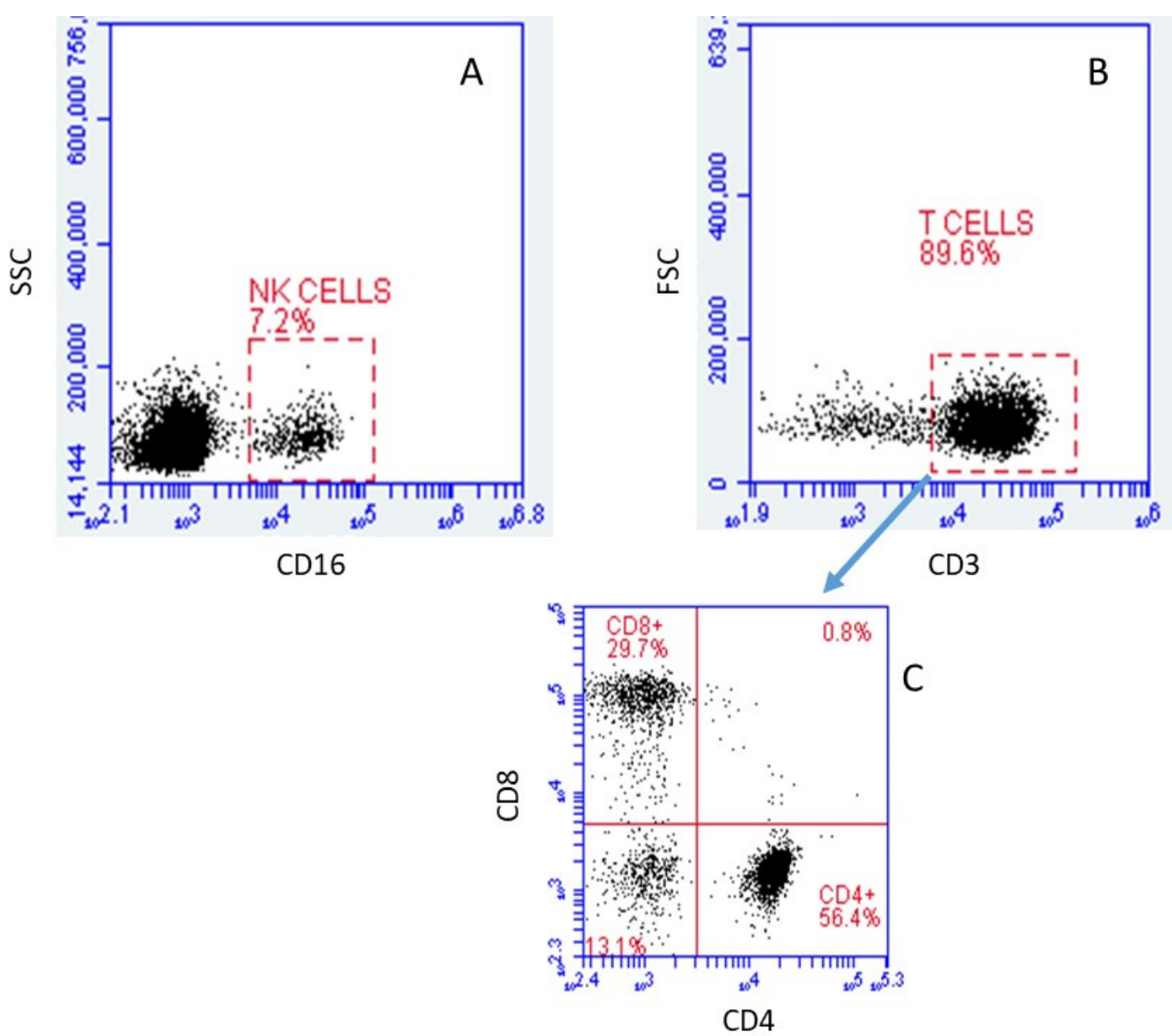

Figure 1. Immunophenotyping via flow cytometry analysis of cells obtained after T Cell enrichment by high affinity negative selection human T cell enrichment columns (SSC: Side scattering; FSC: Forward scattering). (A) Relative size vs. CD16 relative intensity, gated on CD45+. (B) Relative granularity vs. CD3 relative intensity, gated on lymphocytes. (C) CD8 vs. CD4 relative intensities, gated on T cells. Of the CD45+ population, $7.2 \%$ were positive for CD16, while $89.6 \%$ of the lymphocyte population was positive for CD3. Cells that were positive for CD4 or CD8 (but not both) accounted for $56.4 \%$ and $29.7 \%$ of CD3+ cells, respectively. 


\subsubsection{Quality of Single-Cell RNA Sequencing}

The sequencing results revealed that we captured 690 control and 733 irradiated cells, as analyzed from a mean of 35 million paired-end reads per sample (Table 1). We were able to detect over 1000 genes that were associated with a cell barcode and contained at least 1 unique molecular identifier (UMI) in both samples. Most of the genes were represented by multiple UMIs illustrated by the sequencing saturation. Both of the samples reached a sequencing saturation over $80 \%$ a representation of high sequencing depth. Furthermore, both samples had greater than $97 \%$ barcode efficiency, meaning that we can confidently map these reads to individual cells and not ambient RNA or noise. The percentages of Q30 bases in barcode were $96.3 \%$ and $96.4 \%$ for the control and irradiated samples, respectively (Table 1). This is an indication that high-quality barcoded information is passing the filter and the majority of the barcodes are not being analyzed by the downstream algorithms. Figure S1A,B show further quality-control analytics. Knee plots for both the control and radiated samples show the cumulative distribution of barcodes counts vs. that of the UMI counts on a log-log scale. Barcodes that are likely associated with a cell (those that have relatively high UMI's) are designated in green (green arrow) [21]. By contrast, the preponderance of barcodes has relatively low UMI counts and they are considered to be associated with noise. The steep drop-off (see red arrow) in the numbers of UMIs for most barcodes that represent actual cells, as opposed to barcodes that are associated with noise, is suggestive of the unbiased identification of actual cells. For both samples, the median UMI count is about 3500 for barcodes that are thought to represent actual cells. Overall, about $0.001 \%$ of the distribution of UMIs sequenced correspond to noise.

Table 1. Quality of the single cell RNA-seq analysis.

\begin{tabular}{ccc}
\hline Sequencing Parameters & Control & Irradiated \\
\hline Cell Number & 690 & 733 \\
Total Reads & 40 Million & 31 Million \\
Genes per Cell & 1131 & 1067 \\
Valid Barcodes & $97.8 \%$ & $97.7 \%$ \\
Sequencing Saturation & $87.1 \%$ & $83.6 \%$ \\
Barcode Q30 & $96.4 \%$ & $96.3 \%$ \\
\hline
\end{tabular}

\subsection{Identification of Lymphocyte Subpopulations Based on scRNA-seq}

Of the 690 irradiated and 733 control cells, five from each treatment group had a total UMI $>7000$ and they were excluded from the analysis on the assumption that for these large UMI counts, more than one cell may have been captured and tagged as a single cell. The remaining 1413 cells, 685 irradiated and 728 controls, are plotted in Figure 2. Figure 2A shows the unsupervised t-Stochastic Neighbor Embedding (t-SNE) plot from the unbiased clustering of all irradiated and control cells that are based on the UMI in each of the genes in each cell. A graph-based hierarchical clustering algorithm was also used to separate the cells into three groups (three different colors) (Figure 2B). Heat diagrams, as shown in Figure 2C, were then used to identify predominant genes within each group. Cluster 3 is distinguished by expression of a set of genes, including CCL4, GNLY, CST7, PRF1, CCL5, which have been identified as signature genes for CD8+/NK cells [22]. Cluster 2 is characterized by the expression of CCR7 and SELL that are well-known marker genes for naïve cells $[23,24]$. The remaining cells that did not belong to cluster 2 or 3 were then predominately CD4+ cells (cluster 1). The total cell number of the clusters 1, 2, and 3 were 603,412 , and 398, respectively. After excluding $7.2 \%$ NK cells, the ratio of CD4+ to CD8+ cells found based on UMI values was about 2:1, which is similar to the ratio that is shown in Figure 1. 
(A)

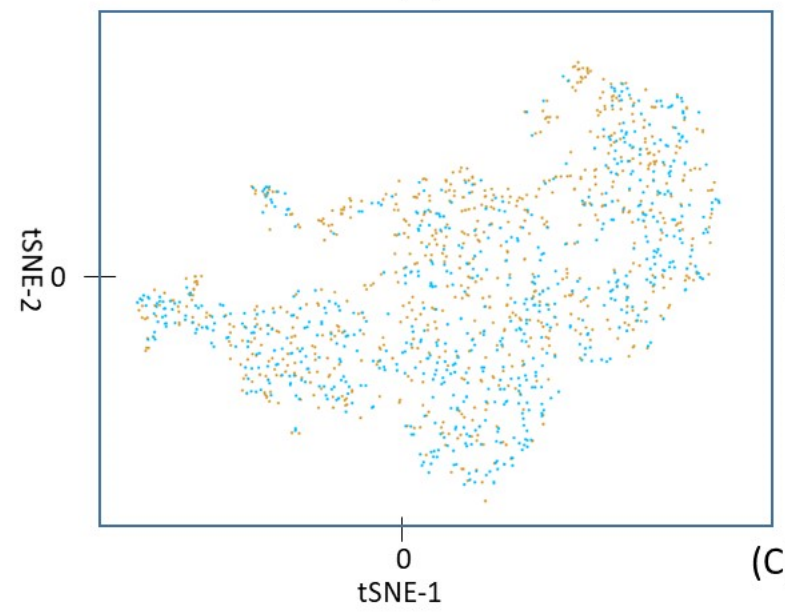

(B)

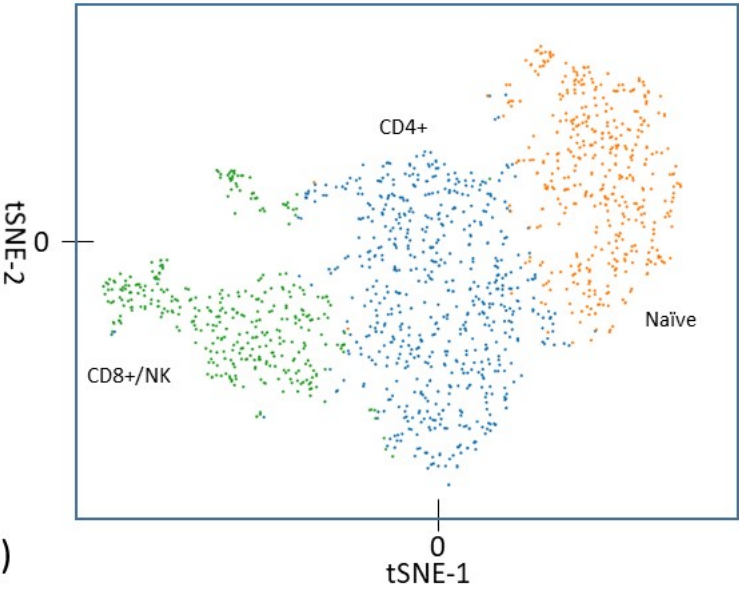

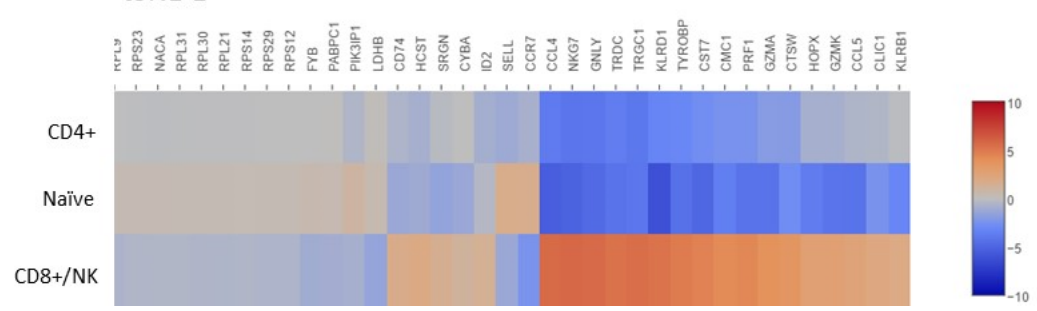

Figure 2. (A) Unsupervised t-SNE analysis of the UMI counts in the irradiated (orange) and control (blue) cells. (B) A graph-based hierarchical clustering algorithm separated the cells into three groups (clusters), shown as three different colors. (C) Heat diagram of gene expression in each of the three clusters. Marker genes identified cluster 1 (blue in B) as CD4+ cells, cluster 2 (orange in B) as naïve cells and cluster 3 (green in B) as CD8+/NK cells. The naïve cells include both naïve CD4+ and naïve CD8+ cells.

\subsection{Gene Expression in T cells Subpopulations}

Using the negative binomial regression method, the gene expression patterns of the irradiated and non-irradiated cells were compared in each of the clusters (cell subtypes) separately, as well as for all cell subtypes in combination. Generally, the expression of all genes before and after radiation exposure showed a more accurate fit to a negative binomial distribution than to a Poisson distribution. A representative example for the distribution of phosphohistidine phosphatase 1 (PHPT1) gene expression post irradiation is shown in Figure S2. Tables 2 and 3 include the list of genes that were upregulated and downregulated, with a fold change threshold of 2 and $p$-values of less than 0.001 after radiation exposure. Genes that did not meet the criteria are shown in gray. Upregulated genes are mostly TP53 related genes, including FDXR, BBC3, CD70, and AEN (Table 2). Most of the genes that were significantly upregulated in the cell population as a whole were also upregulated in one or more of the single cell subtypes. However, interestingly, IRF1, STAT1, and BATF were upregulated in $\mathrm{CD} 4+$ and naïve cells, but were unchanged in CD8+/NK cells. Among the downregulated 34 genes, DNAJB1, ISG20, CRIP1, IFITM1, and HSPA1A were the most remarkable (Table 3). An example of significant dysregulated genes after radiation is represented in Figure 3. FDXR and BBC3 were upregulated, whereas HSPA1A was downregulated, in all three cell subtypes whereas STAT1 and IRF1 ware upregulated in CD4+ and naïve cells, but they did not change in CD8+/NK cells. 
Table 2. Genes whose expressions were upregulated signicantly when all of the cells or cells in individual cell types were considered. The genes meet the criteria of Fold Change $(\mathrm{FC})>2\left(\log _{2} \mathrm{FC}>1\right)$ and $p<0.001$

\begin{tabular}{|c|c|c|c|c|c|c|c|c|}
\hline Gene & All Cells $\log _{2} \mathrm{FC}$ & $p$ & $\mathrm{CD} 4+\log _{2} \mathrm{FC}$ & $p$ & $\mathrm{CD} 8+/ \mathrm{NK} \log _{2} \mathrm{FC}$ & $p$ & Naïve $\log _{2}$ FC & $p$ \\
\hline FDXR & 4.05 & $5.9 \times 10^{-16}$ & 3.63 & $5.2 \times 10^{-9}$ & 4.52 & $1.7 \times 10^{-5}$ & 4.90 & $8.9 \times 10^{-4}$ \\
\hline$B B C 3$ & 4.00 & $0.0 \times 10^{+00}$ & 4.23 & $4.2 \times 10^{-29}$ & 3.44 & $1.6 \times 10^{-18}$ & 4.34 & $2.3 \times 10^{-20}$ \\
\hline CD70 & 2.99 & $2.6 \times 10^{-9}$ & 4.17 & $2.8 \times 10^{-6}$ & 1.75 & & 2.58 & $1.1 \times 10^{-1}$ \\
\hline$A E N$ & 3.15 & $6.1 \times 10^{-30}$ & 3.31 & $2.3 \times 10^{-17}$ & 2.83 & $1.8 \times 10^{-6}$ & 3.06 & $1.2 \times 10^{-8}$ \\
\hline FHL2 & 3.08 & $5.3 \times 10^{-4}$ & 2.95 & $7.9 \times 10^{-3}$ & 2.29 & & & \\
\hline PCNA & 2.94 & $0.0 \times 10^{+00}$ & 3.20 & $6.1 \times 10^{-25}$ & 3.53 & $2.8 \times 10^{-14}$ & 2.04 & $2.9 \times 10^{-7}$ \\
\hline$D D B 2$ & 2.87 & $0.0 \times 10^{+00}$ & 3.17 & $1.5 \times 10^{-21}$ & 2.82 & $7.3 \times 10^{-11}$ & 2.49 & $4.0 \times 10^{-12}$ \\
\hline GADD45A & 2.79 & $1.5 \times 10^{-15}$ & 2.66 & $6.0 \times 10^{-9}$ & 5.64 & $1.3 \times 10^{-4}$ & 1.47 & $1.9 \times 10^{-2}$ \\
\hline ATF3 & 2.33 & $4.8 \times 10^{-4}$ & 4.20 & $5.6 \times 10^{-3}$ & 1.78 & & 0.77 & $4.5 \times 10^{-1}$ \\
\hline CDKN1A & 2.08 & $3.6 \times 10^{-4}$ & 3.65 & $6.0 \times 10^{-4}$ & & $8.1 \times 10^{-1}$ & 0.77 & $6.6 \times 10^{-1}$ \\
\hline TNFSF8 & 2.39 & $1.4 \times 10^{-12}$ & 2.22 & $2.9 \times 10^{-8}$ & 2.72 & $4.3 \times 10^{-4}$ & 3.02 & $5.6 \times 10^{-3}$ \\
\hline РHРT1 & 2.07 & $0.0 \times 10^{+00}$ & 2.46 & $7.2 \times 10^{-30}$ & 1.57 & $6.8 \times 10^{-9}$ & 1.97 & $3.6 \times 10^{-14}$ \\
\hline ACTA2 & 2.08 & $6.1 \times 10^{-6}$ & 1.95 & $1.4 \times 10^{-3}$ & 2.29 & $3.8 \times 10^{-3}$ & & \\
\hline RPS27L & 2.06 & $0.0 \times 10^{+00}$ & 2.14 & $0.0 \times 10^{+00}$ & 2.04 & $1.6 \times 10^{-33}$ & 1.93 & $0.0 \times 10^{+00}$ \\
\hline MDM2 & 1.95 & $7.0 \times 10^{-8}$ & 1.46 & $1.7 \times 10^{-3}$ & 4.67 & & 1.70 & $1.9 \times 10^{-2}$ \\
\hline TNFRSF10B & 1.89 & $1.3 \times 10^{-5}$ & 2.00 & $9.8 \times 10^{-4}$ & 1.97 & & 1.54 & $3.6 \times 10^{-2}$ \\
\hline FAS & 1.87 & $3.9 \times 10^{-12}$ & 2.06 & $7.4 \times 10^{-9}$ & 1.60 & $1.4 \times 10^{-3}$ & 1.58 & $2.5 \times 10^{-2}$ \\
\hline$B A X$ & 1.85 & $0.0 \times 10^{+00}$ & 1.93 & $7.1 \times 10^{-37}$ & 1.68 & $8.2 \times 10^{-16}$ & 2.03 & $3.1 \times 10^{-21}$ \\
\hline ASCC 3 & 1.67 & $2.5 \times 10^{-9}$ & 1.68 & $4.5 \times 10^{-5}$ & 1.60 & $2.3 \times 10^{-3}$ & 1.69 & $2.5 \times 10^{-03}$ \\
\hline PRDM1 & 1.66 & $8.0 \times 10^{-4}$ & 1.69 & $1.2 \times 10^{-2}$ & 1.11 & $1.6 \times 10^{-1}$ & & \\
\hline TRIAP1 & 1.62 & $1.2 \times 10^{-17}$ & 1.85 & $1.3 \times 10^{-10}$ & 1.66 & $3.3 \times 10^{-5}$ & 1.19 & $2.7 \times 10^{-4}$ \\
\hline FBXO22 & 1.52 & $1.5 \times 10^{-7}$ & 1.95 & $3.6 \times 10^{-5}$ & 1.55 & & 1.02 & $2.3 \times 10^{-2}$ \\
\hline ARHGEF3 & 1.50 & $6.5 \times 10^{-9}$ & 0.92 & $1.1 \times 10^{-2}$ & 2.34 & $3.5 \times 10^{-4}$ & 1.90 & $8.4 \times 10^{-5}$ \\
\hline TIGAR & 1.50 & $3.6 \times 10^{-5}$ & 1.30 & $1.2 \times 10^{-2}$ & 1.25 & $5.4 \times 10^{-2}$ & 2.36 & $1.1 \times 10^{-2}$ \\
\hline STAT1 & 1.32 & $1.2 \times 10^{-8}$ & 1.42 & $1.3 \times 10^{-5}$ & -0.27 & $6.9 \times 10^{-1}$ & 1.55 & $3.3 \times 10^{-5}$ \\
\hline АРОВЕСЗС & 1.39 & $4.2 \times 10^{-7}$ & 1.41 & $1.3 \times 10^{-3}$ & 1.65 & $1.4 \times 10^{-4}$ & 0.99 & $1.1 \times 10^{-1}$ \\
\hline$X P C$ & 1.33 & $3.8 \times 10^{-14}$ & 1.22 & $9.0 \times 10^{-7}$ & 0.92 & $6.7 \times 10^{-3}$ & 1.99 & $1.9 \times 10^{-7}$ \\
\hline SESN1 & 1.30 & $6.6 \times 10^{-10}$ & 1.66 & $2.1 \times 10^{-6}$ & 1.11 & & 0.95 & $9.7 \times 10^{-3}$ \\
\hline$I K B I P$ & 1.26 & $3.2 \times 10^{-5}$ & 1.58 & $1.1 \times 10^{-3}$ & 1.23 & $3.6 \times 10^{-02}$ & 0.97 & $7.5 \times 10^{-2}$ \\
\hline$H D L B P$ & 1.18 & $9.2 \times 10^{-4}$ & 1.25 & $1.7 \times 10^{-2}$ & 1.55 & & & $2.4 \times 10^{-1}$ \\
\hline ZMAT3 & 1.15 & $1.8 \times 10^{-04}$ & 1.45 & & 0.80 & & 0.77 & $2.1 \times 10^{-1}$ \\
\hline TRIM22 & 1.15 & $1.5 \times 10^{-10}$ & 1.04 & $1.4 \times 10^{-5}$ & 1.52 & $5.2 \times 10^{-4}$ & 1.07 & $2.0 \times 10^{-3}$ \\
\hline BATF & 1.08 & $2.7 \times 10^{-4}$ & 1.44 & $6.7 \times 10^{-4}$ & 0.05 & $9.3 \times 10^{-1}$ & 1.77 & $1.1 \times 10^{-2}$ \\
\hline IRF1 & 1.03 & $1.3 \times 10^{-23}$ & 1.29 & $2.5 \times 10^{-17}$ & 0.04 & $8.5 \times 10^{-1}$ & 1.09 & $1.9 \times 10^{-10}$ \\
\hline$M A P 4 K 4$ & 1.01 & $1.8 \times 10^{-4}$ & & & 1.19 & & 1.44 & $3.9 \times 10^{-3}$ \\
\hline NINJ1 & & $2.7 \times 10^{-06}$ & 1.22 & $7.3 \times 10^{-5}$ & & $5.2 \times 10^{-2}$ & 0.67 & $5.8 \times 10^{-2}$ \\
\hline
\end{tabular}


Table 3. Genes whose expressions were downregulated signicantly when all of the cells or cells in individual cell types were considered. The genes meet the criteria of Fold Change $(\mathrm{FC})>2\left(\log _{2} \mathrm{FC}<-1\right)$ and $p<0.001$.

\begin{tabular}{|c|c|c|c|c|c|c|c|c|}
\hline Gene & All Cells $\log _{2}$ FC & $p$ & $\mathrm{CD} 4+\log _{2} \mathrm{FC}$ & $p$ & $\mathrm{CD} 8+/ \mathrm{NK} \log _{2} \mathrm{FC}$ & $p$ & Naïve $\log _{2}$ FC & $p$ \\
\hline CRIP1 & -1.02 & $2.6 \times 10^{-9}$ & -1.03 & $1.1 \times 10^{-6}$ & -1.16 & $2.4 \times 10^{-3}$ & -0.64 & $1.1 \times 10^{-1}$ \\
\hline METAP1 & -1.05 & $2.2 \times 10^{-4}$ & & & -1.39 & $4.1 \times 10^{-2}$ & -1.01 & $3.8 \times 10^{-2}$ \\
\hline ISG20 & -1.02 & $5.2 \times 10^{-13}$ & -1.28 & $3.1 \times 10^{-9}$ & -0.84 & $4.5 \times 10^{-3}$ & & $1.6 \times 10^{-3}$ \\
\hline DNAJB1 & -1.03 & $2.7 \times 10^{-14}$ & -0.61 & $1.0 \times 10^{-3}$ & -0.77 & $4.3 \times 10^{-3}$ & -1.46 & $9.7 \times 10^{-10}$ \\
\hline CEBPD & -1.03 & $9.8 \times 10^{-4}$ & -1.69 & $1.4 \times 10^{-2}$ & -0.84 & $1.2 \times 10^{-2}$ & $\begin{array}{l}1.70 \\
-2.23\end{array}$ & $1.7 \times 10^{-1}$ \\
\hline$D B F 4$ & -1.04 & $9.8 \times 10^{-5}$ & -0.62 & $8.4 \times 10^{-2}$ & -1.96 & $8.2 \times 10^{-3}$ & & $5.1 \times 10^{-3}$ \\
\hline ELMOD3 & -1.04 & $8.4 \times 10^{-4}$ & -0.91 & $3.9 \times 10^{-2}$ & -2.53 & $5.2 \times 10^{-3}$ & & $3.3 \times 10^{-1}$ \\
\hline NDUFA7 & $\begin{array}{l}-1.07 \\
-1.05\end{array}$ & $6.7 \times 10^{-4}$ & -1.31 & $1.8 \times 10^{-2}$ & -0.69 & $1.9 \times 10^{-1}$ & -1.04 & $4.7 \times 10^{-2}$ \\
\hline LINC00954 & -1.07 & $7.7 \times 10^{-04}$ & -1.05 & $3.1 \times 10^{-2}$ & -1.77 & $6.3 \times 10^{-2}$ & -1.09 & $2.5 \times 10^{-2}$ \\
\hline SHOC2 & -1.10 & $1.8 \times 10^{-5}$ & -1.05 & $5.4 \times 10^{-3}$ & -1.56 & $8.6 \times 10^{-03}$ & & $8.3 \times 10^{-2}$ \\
\hline TSEN54 & -1.09 & $9.8 \times 10^{-5}$ & -0.86 & $5.9 \times 10^{-2}$ & -1.80 & $5.3 \times 10^{-4}$ & & $2.5 \times 10^{-1}$ \\
\hline THEMIS2 & -1.20 & $6.7 \times 10^{-04}$ & -1.70 & $6.6 \times 10^{-3}$ & -1.28 & $4.7 \times 10^{-2}$ & & $5.6 \times 10^{-01}$ \\
\hline WDR20 & -1.13 & $3.3 \times 10^{-4}$ & & $6.0 \times 10^{-2}$ & -1.94 & $1.7 \times 10^{-2}$ & -1.09 & $4.4 \times 10^{-2}$ \\
\hline CXCR3 & -1.17 & $2.0 \times 10^{-5}$ & -1.63 & $3.2 \times 10^{-4}$ & -0.65 & $6.2 \times 10^{-2}$ & & \\
\hline PCYT1A & -1.16 & $4.0 \times 10^{-4}$ & $\begin{array}{l}1.00 \\
-1.14\end{array}$ & $1.0 \times 10^{-2}$ & -0.67 & $3.2 \times 10^{-1}$ & -1.81 & $1.5 \times 10^{-2}$ \\
\hline CCDC65 & -1.18 & $2.6 \times 10^{-4}$ & -1.15 & $1.4 \times 10^{-2}$ & -0.52 & $5.4 \times 10^{-1}$ & -1.55 & $4.2 \times 10^{-3}$ \\
\hline IFITM1 & -1.18 & $4.6 \times 10^{-7}$ & -1.42 & $8.2 \times 10^{-5}$ & -1.57 & $4.6 \times 10^{-3}$ & -0.70 & $6.5 \times 10^{-2}$ \\
\hline$S F 3 A 2$ & -1.20 & $1.8 \times 10^{-4}$ & $\begin{array}{r}1.72 \\
-1.00\end{array}$ & $3.0 \times 10^{-2}$ & -1.80 & $1.5 \times 10^{-2}$ & -1.15 & $5.4 \times 10^{-2}$ \\
\hline DOK2 & -1.23 & $1.5 \times 10^{-4}$ & -1.56 & $1.3 \times 10^{-3}$ & -0.72 & $2.3 \times 10^{-1}$ & -1.23 & $9.5 \times 10^{-2}$ \\
\hline$C D C 14 A$ & -1.23 & $5.8 \times 10^{-4}$ & -1.21 & $1.5 \times 10^{-2}$ & -0.55 & $4.6 \times 10^{-1}$ & -1.81 & $1.6 \times 10^{-2}$ \\
\hline ABHD3 & -1.22 & $6.9 \times 10^{-6}$ & -1.52 & $1.4 \times 10^{-4}$ & -0.15 & $8.0 \times 10^{-1}$ & -1.41 & $6.7 \times 10^{-3}$ \\
\hline APBB1 & $\begin{array}{l}-1.29 \\
-1.29\end{array}$ & $8.7 \times 10^{-4}$ & $\begin{array}{l}-1.02 \\
-1.97\end{array}$ & $6.9 \times 10^{-3}$ & -0.77 & $3.0 \times 10^{-1}$ & -1.15 & $5.4 \times 10^{-2}$ \\
\hline YPEL2 & -1.39 & $4.4 \times 10^{-4}$ & -2.63 & $7.3 \times 10^{-4}$ & & & -0.64 & $2.0 \times 10^{-1}$ \\
\hline RP11284N83 & -1.41 & $9.5 \times 10^{-4}$ & -3.11 & $4.2 \times 10^{-4}$ & -0.25 & $7.5 \times 10^{-1}$ & -0.23 & $7.7 \times 10^{-1}$ \\
\hline SNAPC2 & -1.48 & $1.4 \times 10^{-4}$ & $\begin{array}{l}-1.11 \\
-1.80\end{array}$ & $1.9 \times 10^{-3}$ & -1.73 & $3.9 \times 10^{-2}$ & -0.97 & $1.9 \times 10^{-1}$ \\
\hline HSPA1B & -1.52 & $1.4 \times 10^{-4}$ & -1.63 & $2.3 \times 10^{-2}$ & -1.79 & $5.4 \times 10^{-2}$ & -1.54 & $3.7 \times 10^{-3}$ \\
\hline NFKBID & -1.70 & $5.0 \times 10^{-5}$ & -1.51 & $8.4 \times 10^{-2}$ & -0.84 & $1.9 \times 10^{-1}$ & -3.23 & $2.6 \times 10^{-4}$ \\
\hline HSPA1A & -1.76 & $1.4 \times 10^{-7}$ & -2.46 & $3.0 \times 10^{-6}$ & -1.42 & $5.2 \times 10^{-2}$ & -1.72 & $9.1 \times 10^{-4}$ \\
\hline ERI1 & -1.83 & $9.2 \times 10^{-4}$ & -2.63 & $3.7 \times 10^{-3}$ & -0.35 & $7.1 \times 10^{-1}$ & -2.04 & $7.8 \times 10^{-2}$ \\
\hline HAUS7 & -2.05 & $1.8 \times 10^{-4}$ & -1.99 & $3.2 \times 10^{-3}$ & -1.62 & $3.3 \times 10^{-1}$ & -2.40 & $3.3 \times 10^{-2}$ \\
\hline LZTS2 & -2.20 & $7.5 \times 10^{-4}$ & -0.53 & $5.3 \times 10^{-1}$ & & $2.7 \times 10^{-2}$ & & \\
\hline EGR1 & -2.29 & $2.4 \times 10^{-}$ & -1.63 & $1.0 \times 10^{-1}$ & -2.84 & $4.9 \times 10^{-2}$ & -2.48 & $9.5 \times 10^{-3}$ \\
\hline GZMH & -2.60 & $3.2 \times 10^{-4}$ & & & -2.03 & $5.4 \times 10^{-3}$ & & \\
\hline
\end{tabular}




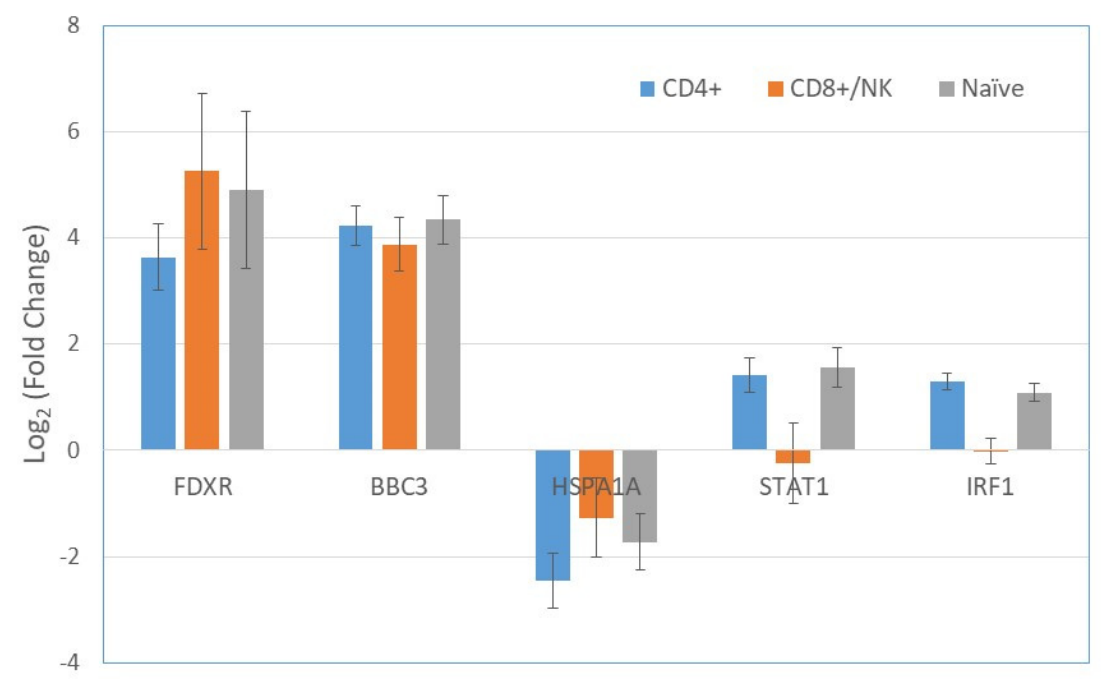

Figure 3. Fold changes of gene expression in selected genes after radiation exposure in the 3 clusters of $\mathrm{CD} 4+, \mathrm{CD} 8+/ \mathrm{NK}$, and naïve cells. FDXR and BBC3 were upregulated by radiation, whereas HSPA1A was downregulated, in all three groups. The upregulation of STAT1 and IRF1 was found in CD4+ and naïve cells, but not in CD8+/NK cells. Bars represent the standard error of the mean.

\subsection{Pathway Analysis}

Genes with significant expression changes in cells of all subpopulations combined were further studied with Ingenuity Pathway Analysis (IPA) to determine the pathways that respond to radiation exposure. As expected, radiation exposure upregulated the TP53 response (Figure 4A). The IRF1/STAT1 network was also activated, which involved the upregulation of genes, including BAFT (Figure 4B).

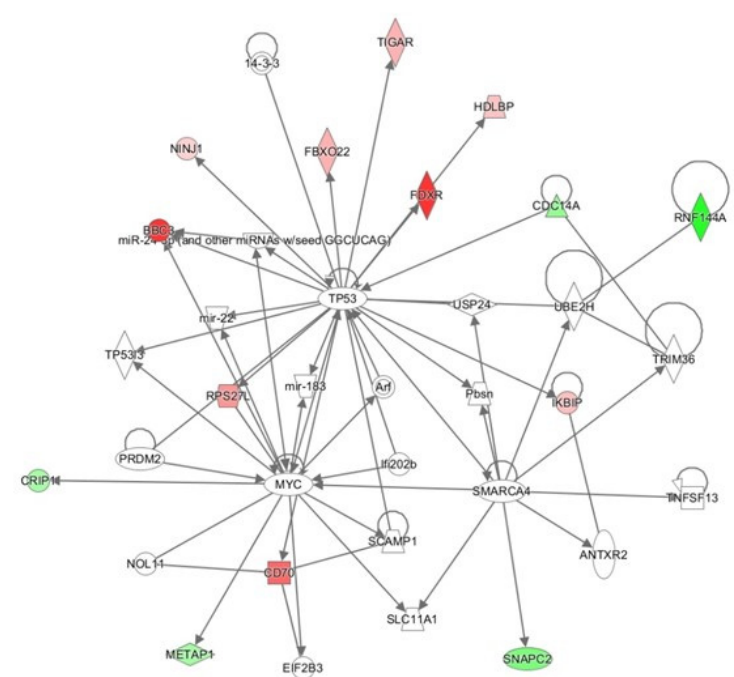

(A)

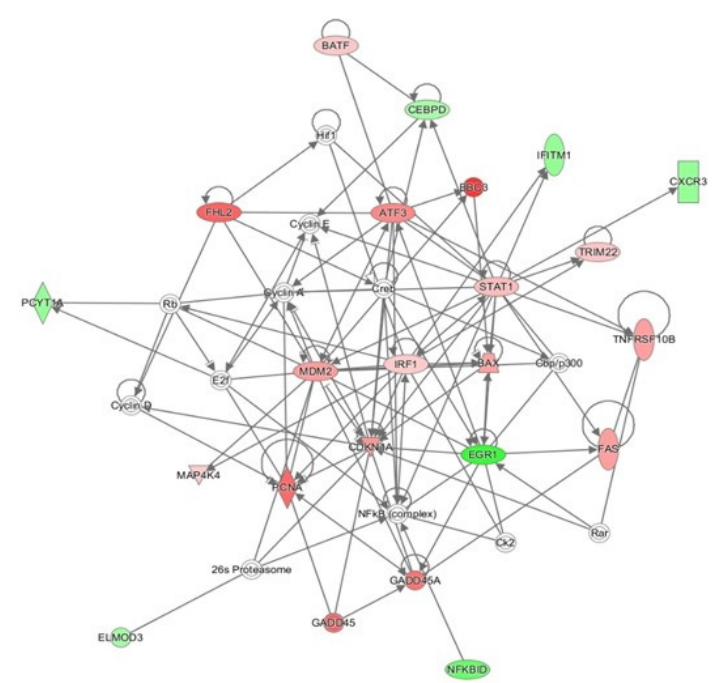

(B)

Figure 4. IPA analysis of the genes whose expressions were significantly altered when all cells were considered indicated that (A) TP53 is the primary response to radiation exposure in human T cells after 2 Gy gamma irradiation, and (B) activation of the STAT1/IRF1 signaling pathway in the irradiated cells.

When pathway analysis was performed for each of the cell subtypes, TP53 remains the top upstream regulator for all three subtypes, as determined by the Z-value (Table 4). Significant upstream regulators are those with a Z-value above 2. Notably, STAT1 and IRF1 were only upstream regulators in CD4+ and naïve cells, but not in CD8+/NK cells. These two genes, in combination with BAFT, which is regulated by STAT1, did not change expression in CD8+/NK cells (Figure 3). 
Table 4. Z-value of the upstream regulators identified in each of the three clusters generated by Ingenuity Pathway Analysis (IPA). Significantly regulated genes were defined by fold $>2.0$ and $p<0.001$. STAT1 and IRF1 had a Z value below 2 in only the CD8+/NK cells.

\begin{tabular}{cccc}
\hline & CD4+ & CD8+/NK & Naïve \\
\hline TP53 & 4.51 & 3.8 & 3.58 \\
TP63 & 2.96 & 2.44 & 2.58 \\
NFATC2 & 2.35 & 1.11 & 1.91 \\
STAT1 & 2.28 & 0.54 & 2.74 \\
IRF1 & 2.19 & 1.09 & 2.36 \\
TP73 & 2.15 & 2.57 & 1.51 \\
STAT5B & -2.61 & -2.19 & -2.22 \\
STAT5A & -2.14 & -2.19 & -2.2 \\
\hline
\end{tabular}

\subsection{Hierarchical Clustering}

Hierarchical clustering of the distance matrix that was obtained with bivariate negative-binomial modeling was performed to identify genes that are potentially associated with each other in response to radiation exposure. The upregulated genes were clearly separated into two clusters, one involving genes in the TP53 network and the other in the STAT1/IRF1 network (Figure 5). In addition, our clustering analysis showed high correlations between CD70 and PRDM1, and between ASCC3 and MAP4K4. The downregulated genes had low UMI counts, even in unirradiated control cells, and thus their data could not be included in the bivariate negative binomial modeling.

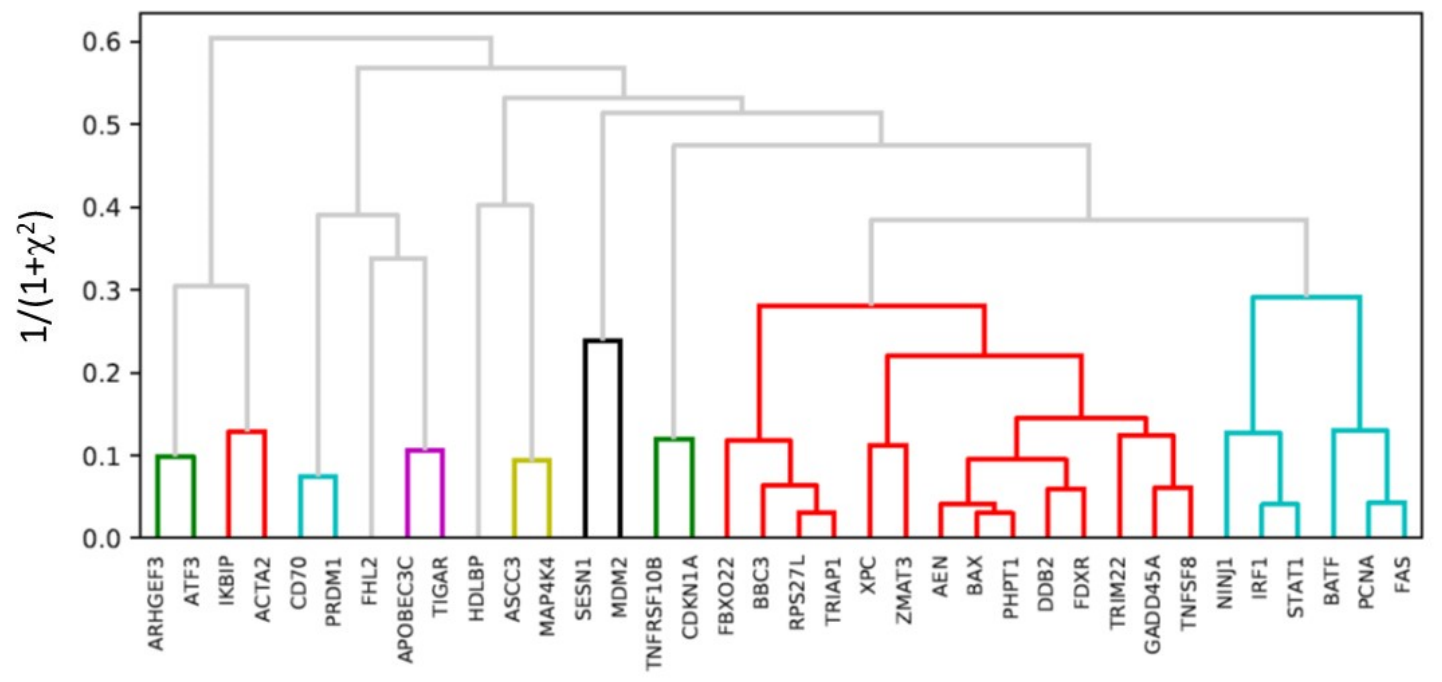

Figure 5. Hierarchical clustering of the radiation response genes from the expression in all of the individual cells that were irradiated. Genes that are involved in TP53 signaling pathways (AEN, PHPT1 and etc.) and STAT1 signaling pathways (IRF1, FAS, BATF, NINJ1, and FCNA) are grouped together, indicating that these were the two primary pathways in response to radiation exposure in $\mathrm{T}$ cells.

\section{Discussion}

Although the scRNA-seq has been used in the past to analyze human blood cells [25], most of these studies focused on identifying new types of blood cells, revealing regulatory relationships [26] or comparing transcriptomic profiles between blood and tumor cells [13]. Here, we report gene expression in individual $\mathrm{T}$ cells in response to ex vivo radiation exposure. Our goal was to determine whether different cells and different subtypes of $T$ cells respond differently to radiation-induced DNA damage. Different from the study by Villani and Shekhar [25], we did not further separate CD4+ and CD8+ cells into effector memory, central memory, and effector cells. The ratio of CD4+ to CD8+ cells was 
about 1 in [25], which is different from the present study. However, it is known that such a ratio can vary between individuals.

In the present study, 728 cells that were irradiated with 2 Gy gamma rays and 685 non-exposed cells were analyzed for gene expression using the 10X Genomics system. Clustering analysis separated the cells into three groups that correspond to $\mathrm{CD} 4+, \mathrm{CD} 8+/ \mathrm{NK}$, and naïve cells, as determined by the marker genes (Figure 2). The percentages of these cell subtypes were similar to the results that were obtained from flow cytometry analysis with surface markers (Figure 1). After radiation exposure, a number of genes had significant changes in expression, as shown in Table 2. Most of these genes, including FDXR, BBC3, PCNA, and GADD5A, are known to be upregulated in blood cells after radiation exposure (Figure 3), and to be regulated by TP53 (Figure 4A). Radiation-induced gene expression changes in peripheral blood mononuclear cells (PBMC) have been studied in the past [18] and an extended list of genes has recently been suggested as the potential biomarkers of radiation exposure [27]. Most of the genes that were upregulated in the present study have been listed as the candidate genes for potential biodosimetry applications [26]. When all subtypes of cells in the present study were considered, the fold changes in gene expressions were as high as 16 for FDXR and BBC 3 at three hours after radiation exposure (Table 2) [28].

Our present study demonstrated that scRNA-seq is useful for simultaneously analyzing the expression of a set of genes in different subtypes of human $\mathrm{T}$ cells after radiation exposure. Previous studies have reported radiation-induced changes in gene expression in subtypes of blood cells; however, each cell type was analyzed separately in these studies [29,30]. Riecke et al. [29] reported that patterns of expression of GADD45, DDB2, CDKN1A, PCNA, BAX, and ATF3 genes were similar in the CD4+ and CD8+ cells after X-ray irradiation, whereas Gruel et al. [30] only reported gene expression changes in $\mathrm{CD} 4+$ or $\mathrm{CD} 8+$ cells for some of the genes. In the present study, most radiation responsive genes, such as FDXR, PCNA, and DDB2, were upregulated in the CD4+, CD8+/NK, and naïve cell types (Table 2), although some of the gene expression changes were not significant, as determined by the p-value criteria, because only a small number of cells were analyzed for each subtype. Our analysis also showed that TP53 is the primary upstream regulator for all cell subtypes (Table 4). A number of genes were down-regulated after radiation exposure (Table 3). Several of those genes, including $D N A J B 1, H S P A 1 A$, and HSPA1B are associated with heat shock responses. Some of the genes only showed significant downregulations when cells from all subpopulations are combined because of low numbers of cells in individual subpopulations to meet the criteria for the $p$ value (Table 3).

In contrast to the common genes upregulated in all of the cell types mentioned, we found that IRF1, STAT1, and BATF were upregulated in CD4+ and naïve cells, in the present study they were not upregulated in CD8+/NK cells (Table 2, Figure 3). The upregulation of these three genes indicates that the interferon gamma pathway is activated in T-cells after radiation exposure. Previous studies have shown that IRF1 and STAT1 expression is associated with radiation exposure [31]. In mouse splenocytes, after 5 Gy gamma irradiation, the phosphorylation of STAT1 turns on specific sets of IFN-gamma-inducible genes, including IRF1 [32]. Furthermore, system biology modeling has identified STAT1 and IRF1 as two of the genes in a network that affect a cell's radio-sensitivity. It is interesting to note that, in the present study, these IFN-gamma-related genes were upregulated in $\mathrm{CD} 4+$ and naïve cells, but not in CD8+/NK cells. One possible explanation for our observation is that $\mathrm{CD} 8+/ \mathrm{NK}$ cells are proliferating, and are therefore more sensitive to radiation-induced apoptosis. Ozsahin et al. [33] reported that 2 Gy gamma rays induced apoptosis in $12.5 \%$ of CD4+ cells, but $20.7 \%$ of CD8+ cells. It has also been reported that IRF1 and STAT1 influence apoptosis in different cell types [34,35]. Further investigation is required to determine whether apoptosis influences measures of radiation-induced expression of IRF1 and STAT1. The activation of STAT and TP53 signaling has also been found in response to etoposide $[36,37]$ and several other genotoxic drugs, such as fludarabine or doxorubicin [38]. The critical importance of STAT1 is demonstrated in the mutations of the STAT1 gene in humans. The loss of the STAT function leads to immune deficiency [39]. Some mechanisms of STAT signaling in immunity and diseases have been recently summarized [40]. There is genetic 
evidence that STAT1 signaling in different cell types produces antagonistic effects on innate immune response [41]. Furthermore, the expression of STAT1 enhanced the effect of IFN-gamma and IFN-beta on the inhibition of human lung cancer cell proliferation, migration, and invasiveness [42]. The clinical benefits of TP53 have been widely described. Specifically, TP53 and other tumour-suppressor genes are emerging as potential guardians of immune integrity for the immune system [43].

In the present study, we also performed correlation analysis of the gene expression in response to radiation exposure between different cells (Figure 5). Such analysis has the potential to identify genes that are associated with each other. As shown in Figure 5, clustering genes that are based on the degree of correlation identified two major clusters. The first cluster contains genes were directly regulated by $T P 53$, including $G A D D 45 A, B A X, X P C$, and $B B C 3$. The other cluster contains NINJ1, IRF1, STAT1, BATF, PCNA, and FAS, which are genes that are known to be associated with interferon-gamma [44]. The identification of the second cluster was also consistent with the findings that upregulation of interferon-associated genes was only found in CD4+ and naïve cells, but not in $\mathrm{CD} 8+/ \mathrm{NK}$ cells. As expected, genes that are highly correlated have known relationships. In addition to IRF1 and STAT1, Figure 5 shows high correlations between PCNA and FAS, between RPS27L and TRIAP1, and between BAX and PHPT1, among others. STAT1 is known to regulate IRF1, and two genes are expected to be highly correlated [45]. However, correlations for other gene pairs are not that obvious. For instance, TP53 has been reported to directly induce RPS27L that in turn promotes apoptosis [46]. On the other hand, TRIAP1 was first characterized as a p53-inducible cell survival factor [47], and the over expression of TRIAP1 protects cells from apoptosis that is caused by DNA damage [48]. The observation in the present study that the expressions of these two genes were highly correlated raised a question as to whether and how they regulate each other.

One of the purposes of the present study was to determine the heterogeneity in a cell population in response to radiation exposure. As shown in Figure S2, the distribution of UMI counts in individual cells in irradiated cells can be better fitted with a negative binomial distribution than the Poisson distribution. This is also true for the distribution of UMI counts in the non-irradiated control cells. The over dispersion was partly caused due to different subpopulations of T cells in the study, in that the distribution of UMI for individual subpopulations was closer to Poisson than for all cells. However, the number of cells for individual subpopulations was low, so the results of such comparisons with the Poisson distribution were not consistent.

The present study was performed with gamma rays. Gamma-induced DNA damage and the consequent cellular responses in individual cells are expected to be similar with variations following the Poisson distribution. However, for space radiation exposure, damage in individual cells will be highly heterogeneous, as only a small fraction of the cells will be traversed by a particle of a specific type and energy at a given time. Non-targeted effects may also affect cells that are not directly traversed by the particles [6]. Therefore, gene expression in response to chronic exposures to a mixture of charged particles is expected to be found in only a fraction of cells at a given time. Damage and damage response in the human body to space radiation exposure will potentially result in health consequences, including cancer [49] and the central nervous system [50].

In summary, the quantification of RNA in individual T cells after radiation exposure allows determination of differential responses in different subpopulations. Out study confirmed that radiation upregulated most of the TP53 related genes. However, the expressions of IRF1, STAT1, and BATF were upregulated in only the CD4+ and naïve groups, but were unchanged in the CD8+/NK group, suggesting that the interferon-gamma pathway does not respond to radiation in CD8+/NK cells.

\section{Materials and Methods}

\subsection{Cells and Radiation Exposure}

Primary human T cells were isolated from source leukocyte samples that were obtained from the Gulf Coast Regional Blood Center, Houston, Texas. To this end, peripheral blood mononuclear 
cells (PBMCs) from one $500 \mathrm{~mL}$ blood donation were separated by density-gradient centrifugation on Ficoll gradients (GE Healthcare, Life Sciences, Piscataway, NJ, USA), followed by red blood cell (RBC) lysis (Human Erythrocyte Lysing Kit, R\&D Systems, Minneapolis, MN, USA). Next, the $T$ cells were purified from the PBMC's using high affinity negative selection human $T$ cell enrichment columns according to the manufacturer's protocol. These columns enabled the removal of B cells (CD19+) and monocytes (CD14+) through binding to the Ig and anti-Ig beads, resulting in a highly enriched $\mathrm{T}$ cell population that was collected in the eluant. The purified $\mathrm{T}$ cells were then resuspended in hydroxyethyl-piperazineethane-sulfonic acid buffer (HEPES) buffered Roswell Park Memorial Institute (RPMI) 1640 medium (Life Technologies/Invitrogen, Carlsbad, CA, USA) that was supplemented with 10\% Fetal Bovine Serum (FBS), 1\% Penicillin/Streptomycin, and $25 \mathrm{mM}$ L-Glutamine (Life Technologies/Invitrogen, Carlsbad, CA). T cell purity (CD45+, CD3+) was assessed by flow cytometric analysis on a Becton Dickinson (BD) Accuri C6 for confirmation of the absence of B cells (CD19+) and monocytes (CD14+). In addition, flow cytometry analysis was also used to determine the ratio of cytotoxic (CD8+) and Helper T cells (CD4+) in the purified T cell sample.

The isolated $\mathrm{T}$ cells were incubated for $16 \mathrm{~h}$ before irradiation. All of the cells were exposed to 2 Gy gamma rays at a high dose rate at NASA Johnson Space Center, Houston, Texas, and were immediately thereafter incubated at $37^{\circ} \mathrm{C}$. The irradiator is annually calibrated with an ion chamber by the manufacture. The non-irradiated cells were kept at room temperature during the radiation time. It has been shown that some genes significantly change their expression between $2-4 \mathrm{~h}$ after radiation [51,52]. Therefore, after $3 \mathrm{~h}$ of incubation $\left(37^{\circ} \mathrm{C}, 95 \%\right.$ relative humidity, and $5 \% \mathrm{CO}_{2}$ concentration), the cells were centrifuged at $300 \mathrm{RCF}$ for $5 \mathrm{~min}$ at $4{ }^{\circ} \mathrm{C}$ and resuspended in pre-chilled TexMacs medium (Miltenyi Biotec, Germany) containing 40\% FBS (Thermal Fisher Scientific, Waltham, MA, USA) at a concentration of $2 \times 10^{7}$ cells $/ \mathrm{mL}$. The cell suspension was placed on ice and resuspended in chilled $2 \times$-freezing medium ( $30 \%$ Dimethyl sulfoxide, DMSO (Sigma, St Luis, MO, USA) in TexMacs medium containing $40 \%$ FCS (Thermal Fisher Scientific, Waltham, MA, USA) at a cell concentration of $1 \times 10^{7}$ cells $/ \mathrm{mL}$. The cryovials were filled with $1 \mathrm{~mL}$ aliquots of cell suspension and then placed in a pre-cooled freezing container at $-80{ }^{\circ} \mathrm{C}$ until RNA isolation procedure was performed. Cell vitality was measured while using Guava ViaCount technology (EMD Millipore, Hayward, CA, USA). All of the irradiated and controlled cells were collected in a single experiment

\subsection{Single Cell RNA-Seq Library Preparation and Sequencing}

Cell quality and viability are essential in producing reliable scRNA-seq data [53]. The process of creating a single cell suspension can stress cells and lead to cell death, which releases ambient cell-free RNA into the suspension. To avoid ambient RNA and minimize the traces of DMSO, which lowers the possible side-effects, such as changes in the transcriptome on downstream molecular assays, cell suspensions were washed 2-4 times and manually counted (using a hemocytometer) twice to assure cell viability was $>90 \%$ before loading onto the Chromium platform. The libraries were created from these cells by successfully capturing cells inside gel beads in emulsion (GEM) by passing cells through a microfluidic channel. Each GEM contains a unique cellular barcode that is added to the lysed cell's mRNA during cDNA formation by reverse transcription PCR. Library fragmentation size and quantification were measured before sequencing to ensure that the cDNA has been fragmented and barcoded correctly. The cDNA libraries were assessed while using an Agilent 2100 Bioanalyzer High-sensitivity DNA chip. For this technique, the average size of the cDNA fragments should be $500 \mathrm{bp}$ and each fragment should encompass read 1 and read 2, a $16 \mathrm{bp} 10 \times$ barcode that maps the reads back to individual cells, a $10 \mathrm{bp}$ molecular identifier (UMI) that is unique for each individual read and used to quantify the transcriptome of the barcoded cell, a 8 bp i7 index read that combines four different sequences per sample to represent all four nucleotides, and Illumina paired-end constructs P5 and P7 primer sites for pair-end sequencing. Both our control and our irradiated samples had an average fragment size of $500 \mathrm{bp}$ (Figure S3), so a $500 \mathrm{bp}$ insert was used to count the number of 
fragments using a Qubit Fluorometer and by qPCR methods (data not shown). Accurate quantification allows for the proper loading of cDNA libraries for sequencing.

On the day of single-cell capture and library preparation, the control and irradiated cells were resuspended in PBS containing 0.04\% bovine serum albumin (BSA) (Ambion, Foster City, CA, USA) to a final concentration of 200 cells per $\mu \mathrm{L}$. This cell suspension was used as an input for automated single-cell capture and barcoding using the 10X Genomics Full Chromium platform. Approximately 700 single cells were captured for each sample while using the 10X Genomics Single Cell 3' Chip (as per manufacturer recommendations Single Cell 3' Reagent Kits v2 User Guide version CG00052) at Seq-N-Edit Core, University of Houston, Houston, Texas, USA. Single cell GEMs were generated and the single cells were uniquely barcoded. The cDNA was recovered and selected using DynaBead MyOne Silane Beads (Thermo Fisher Scientific, Carlsbad, CA, USA) and SPRIselect beads (Beckman Coulter, Brea, CA, USA). The control samples were indexed "CACTCGGA" "GCTGAATT" "TGAAGTAC" or "ATGCTCCG" and the irradiated samples were indexed "CCACTTAT" "AACTGGCG" "TTGGCATA" or "GGTAACGC", which are Illumina sequencer compatible i7 indexes. The sequencing libraries were generated and the quality was assessed using a high-sensitivity DNA chip on 2100 BioAnalyzer (Agilent, Santa Clara, CA, USA), and the fragments were counted with Qubit Fluorometer (Thermo Fisher Scientific, Carlsbad, CA, USA) and Kapa Library Quantification Kit (Kapa Biosystems, Wilmington, MA, USA) using the AriaMX instrument (Agilent, Santa Clara, CA, USA). The libraries were sequenced using NextSeq 500 (Illumina, San Diego, CA, USA) in stand-alone mode to obtain pair end sequencing $26 \mathrm{bp}(\mathrm{read} 1) \times 98 \mathrm{bp}(\mathrm{read} 2)$ and a single index $8 \mathrm{bp}$ in length.

\subsection{Transcriptome Analysis}

Single cell sequencing data downstream analysis was performed on the Maxwell Cluster high-performance research computing center at University of Houston, Houston, Texas, while using the analytical program, Cell Ranger 2.1.1 Single Cell Analysis Pipelines (10X Genomics, Pleasanton, CA, USA). Raw base call files that were generated by Nextseq 500 were demultiplexed using the "cellranger mkfastq" pipeline to FASTQ files. FASTQ files were aligned to the hg38 human reference genome using "cellranger count" using the STAR aligner [54]. The dimensionality of the gene-expression data was reduced to two-dimensions (2-d) using t-Stochastic Neighbor Embedding (tSNE), a nonlinear dimensionality reduction method [55]. A graph-based hierarchical clustering algorithm operating in this two-dimensional space was then used to cluster cells based on similarity of expression. These clusters were then associated with specific sub-type of T-cells (see Results) while using marker genes that were identified from the heat map of relative gene expression values [56].

\subsection{Gene Expression Analysis in Response to Radiation}

Differential gene expression in response to radiation was evaluated using a negative binomial regression model to compare the UMI distribution between the irradiated and control cells. Output from the analysis was an estimated fold change and associated $p$-value for testing the null hypothesis of no effect of radiation. This was done for all of the genes and repeated for each cluster of cells. (Note: When UMI counts for a gene consist of only 0 's and 1's, negative binomial parameters are not estimable and Poisson regression was used instead.) These analyses were implemented while using Stata statistical software (https://www.stata.com/).

\subsection{Pathway Analysis}

Pathway analysis was performed using the Ingenuity Pathway Analysis (IPA) tool (https: //analysis.ingenuity.com/pa/). For each cell cluster separately, and also for all cells combined, IPA was used to generate and rank the pathways based on the fold change and the p-values for the genes with significant expression changes. 


\subsection{Hierarchical Clustering of Genes}

As a way of corroborating the IPA, we used a bivariate negative-binomial model [57] to quantify the dependence of UMI counts between each pair of genes, whose expression was significantly changed after irradiation. In addition, this analyses could identify the pairs of genes not previously known to be related, whose expression values are highly associated. More specifically, dependence was assessed in terms of a chi-squared statistic $(\chi 2)$ after fitting the bivariate negative binomial regression model for each pair of genes. We then performed a non-supervised hierarchical clustering of the distance matrix with average linkage, where the distance function between the genes was defined as $D=1 /(1+\chi 2)$. Clustering was only performed on genes that were significantly upregulated.

Supplementary Materials: Supplementary materials can be found at http://www.mdpi.com/1422-0067/20/9/2316/ s1.

Author Contributions: Conceptualization, H.W., B.C. and P.G.; Methodology, M.M.-V., Y.Z., R.C., M.N.-G., S.K., B.M., Y.P., S.C.; Data Analysis, A.F., W.W.; Writing-Original Draft Preparation, H.W.

Funding: This project was supported by the Office of the Chief Technologist of NASA Johnson Space Center.

Acknowledgments: We would like to thank Dr. Rachana Jain of 10X Genomics for her technical assistance. MMV was supported by the German Research Association (DFG) (Grant \# MO 2243-2-1). YZ was supported by the NASA Space Life and Physical Sciences Research and Applications (SLPSRA) Division.

Conflicts of Interest: The authors declare no conflicts of interest.

\section{References}

1. Cucinotta, F.A.; Durante, M. Cancer risk from exposure to galactic cosmic rays: Implications for space exploration by human beings. Lancet Oncol. 2006, 7, 431-435. [CrossRef]

2. Moreno-Villanueva, M.; Wong, M.; Lu, T.; Zhang, Y.; Wu, H. Interplay of space radiation and microgravity in DNA damage and DNA damage response. NPJ Microgravity 2017, 3, 14. [CrossRef]

3. Hada, M.; Cucinotta, F.A.; Gonda, S.R.; Wu, H. mBAND analysis of chromosomal aberrations in human epithelial cells exposed to low- and high-LET radiation. Radiat. Res. 2007, 168, 98-105. [CrossRef] [PubMed]

4. Furusawa, Y.; Nakano-Aoki, M.; Matsumoto, Y.; Hirayama, R.; Kobayashi, A.; Konishi, T. Equivalency of the quality of sublethal lesions after photons and high-linear energy transfer ion beams. J. Radiat. Res. 2017, 58, 58803-58808.

5. De Toledo, S.M.; Buonanno, M.; Li, M.; Asaad, N.; Qin, Y.; Gonon, G.; Shim, G.; Galdass, M.; Boateng, Y.; Zhang, J.; et al. The impact of adaptive and non-targeted effects in the biological responses to low dose/low fluence ionizing radiation: The modulating effect of linear energy transfer. Health Phys. 2011, 100, $290-292$. [CrossRef] [PubMed]

6. Hei, T.K.; Zhou, H.; Chai, Y.; Ponnaiya, B.; Ivanov, V.N. Radiation induced non-targeted response: Mechanism and potential clinical implications. Curr Mol. Pharmacol. 2011, 4, 96-105. [CrossRef]

7. Desai, N.; Davis, E.; O’Neill, P.; Durante, M.; Cucinotta, F.A.; Wu, H. Immunofluorescence detection of clustered gamma-H2AX foci induced by HZE-particle radiation. Radiat. Res. 2005, 164, 518-522. [CrossRef]

8. Asaithamby, A.; Chen, D.J. Cellular responses to DNA double-strand breaks after low-dose gamma-irradiation. Nucleic Acids Res. 2009, 37, 3912-3923. [CrossRef] [PubMed]

9. Wu, H.; Durante, M.; Furusawa, Y.; George, K.; Kawata, T.; Cucinotta, F.A. Truly incomplete and complex exchanges in prematurely condensed chromosomes of human fibroblasts exposed in vitro to energetic heavy ions. Radiat. Res. 2003, 160, 418-424. [CrossRef]

10. Lu, T.; Zhang, Y.; Wong, M.; Feiveson, A.; Gaza, R.; Stoffle, N.; Wang, H.; Wilson, B.; Rohde, L.; Stodieck, L.; Karouia, F.; Wu, H. Detection of DNA damage by space radiation in human fibroblasts flown on the International Space Station. Life Sci. Space Res. 2017, 12, 24-31. [CrossRef]

11. Hwang, B.; Lee, J.H.; Bang, D. Single-cell RNA sequencing technologies and bioinformatics pipelines. Exp. Mol. Med. 2018, 50, 96. [CrossRef] [PubMed]

12. Zeng, Y.; Novak, R.; Shuga, J.; Smith, M.T.; Mathies, R.A. High-performance single cell genetic analysis using microfluidic emulsion generator arrays. Anal. Chem. 2010, 82, 3183-3190. [CrossRef] 
13. Zheng, C.; Zheng, L.; Yoo, J.K.; Guo, H.; Zhang, Y.; Guo, X.; Kang, B.; Hu, R.; Huang, J.Y.; Zhang, Q.; et al. Landscape of Infiltrating T Cells in Liver Cancer Revealed by Single-Cell Sequencing. Cell 2017, 169, 1342-1356. [CrossRef]

14. Kumar, M.P.; Du, J.; Lagoudas, G.; Jiao, Y.; Sawyer, A.; Drummond, D.C.; Lauffenburger, D.A.; Raue, A. Analysis of Single-Cell RNA-Seq Identifies Cell-Cell Communication Associated with Tumor Characteristics. Cell Rep. 2018, 25, 1458-1468. [CrossRef]

15. Li, N.; van Unen, V.; Abdelaal, T.; Guo, N.; Kasatskaya, S.A.; Ladell, K.; McLaren, J.E.; Egorov, E.S.; Izraelson, M.; Chuva de Sousa Lopes, S.M.; et al. Memory CD4+ T cells are generated in the human fetal intestine. Nat. Immunol. 2019, 20, 301. [CrossRef]

16. Gupta, I.; Collier, P.G.; Haase, B.; Mahfouz, A.; Joglekar, A.; Floyd, T.; Koopmans, F.; Barres, B.; Smit, A.B.; Sloan, S.A.; et al. Single-cell isoform RNA sequencing characterizes isoforms in thousands of cerebellar cells. Nat. Biotechnol. 2018, 36, 1197. [CrossRef] [PubMed]

17. Fernandez-Gonzalo, R.; Baatout, S.; Moreels, M. Impact of Particle Irradiation on the Immune System: From the Clinic to Mars. Front. Immunol. 2017, 8, 177. [CrossRef]

18. Amundson, S.A.; Do, K.T.; Shahab, S.; Bittner, M.; Meltzer, P.; Trent, J.; Fornace, A.J. Identification of potential mRNA biomarkers in peripheral blood lymphocytes for human exposure to ionizing radiation. Radiat. Res. 2000, 154, 342-346. [CrossRef]

19. Tucker, J.D.; Joiner, M.C.; Thomas, R.A.; Grever, W.E.; Bakhmutsky, M.V.; Chinkhota, C.N.; Smolinski, J.M.; Divine, G.W.; Auner, G.W. Accurate gene expression-based biodosimetry using a minimal set of human gene transcripts. Int. J. Radiat. Oncol. Biol. Phys. 2014, 88, 933-939. [CrossRef]

20. Macaeva, E.; Mysara, M.; De Vos, W.H.; Baatout, S.; Quintens, R. Gene expression-based biodosimetry for radiological incidents: Assessment of dose and time after radiation exposure. Int. J. Radiat. Biol. 2019, 95, 64-75. [CrossRef]

21. Macosko, E.Z.; Basu, A.; Satija, R.; Nemesh, J.; Shekhar, K.; Goldman, M.; Tirosh, I.; Bialas, A.R.; Kamitaki, N.; Martersteck, E.M.; et al. Highly Parallel Genome-wide Expression Profiling of Individual Cells Using Nanoliter Droplets. Cell 2015, 161, 1202-1214. [CrossRef] [PubMed]

22. Palmer, C.; Diehn, M.; Alizadeh, A.A.; Brown, P.O. Cell-type specific gene expression profiles of leukocytes in human peripheral blood. BMC Genomics 2006, 7, 115.

23. Berard, M.; Tough, D.F. Qualitative differences between naïve and memory T cells. Immunology 2002, 106, 127-138. [CrossRef]

24. Unsoeld, H.; Pircher, H. Complex memory T-cell phenotypes revealed by coexpression of CD62L and CCR7. J Virol. 2005, 79, 4510-4513. [CrossRef] [PubMed]

25. Villani, A.C.; Shekhar, K. Single-Cell RNA Sequencing of Human T Cells. Methods Mol. Biol. 2017, 1514, 203-239. [PubMed]

26. Zemmour, D.; Zilionis, R.; Kiner, E.; Klein, A.M.; Mathis, D.; Benoist, C. Single-cell gene expression reveals a landscape of regulatory T cell phenotypes shaped by the TCR. Nat. Immunol. 2018, 19, 291-301. [CrossRef] [PubMed]

27. Lacombe, J.; Sima, C.; Amundson, S.A.; Zenhausern, F. Candidate gene biodosimetry markers of exposure to external ionizing radiation in human blood: A systematic review. PLoS ONE 2018, 13, e0198851. [CrossRef]

28. O'Brien, G.; Cruz-Garcia, L.; Majewski, M.; Grepl, J.; Abend, M.; Port, M.; Tichý, A.; Sirak, I.; Malkova, A.; Donovan, E.; et al. FDXR is a biomarker of radiation exposure in vivo. Sci Rep. 2018, 8, 684. [CrossRef] [PubMed]

29. Riecke, A.; Rufa, C.G.; Cordes, M.; Hartmann, J.; Meineke, V.; Abend, M. Gene expression comparisons performed for biodosimetry purposes on in vitro peripheral blood cellular subsets and irradiated individuals. Radiat. Res. 2012, 178, 234-243. [CrossRef]

30. Gruel, G.; Voisin, P.; Vaurijoux, A.; Roch-Lefevre, S.; Grégoire, E.; Maltere, P.; Petat, C.; Gidrol, X.; Voisin, P.; Roy, L. Broad modulation of gene expression in CD4+ lymphocyte subpopulations in response to low doses of ionizing radiation. Radiat. Res. 2008, 170, 335-344. [CrossRef]

31. Gerber, S.A.; Sedlacek, A.L.; Cron, K.R.; Murphy, S.P.; Frelinger, J.G.; Lord, E.M. IFN- $\gamma$ mediates the antitumor effects of radiation therapy in a murine colon tumor. Am. J. Pathol. 2013, 182, 2345-2354. [CrossRef]

32. Han, S.K.; Song, J.Y.; Yun, Y.S.; Yi, S.Y. Gamma irradiation-reduced IFN-gamma expression, STAT1 signals, and cell-mediated immunity. J. Biochem. Mol. Biol. 2002, 35, 583-589. [CrossRef] [PubMed] 
33. Ozsahin, M.; Crompton, N.E.; Gourgou, S.; Kramar, A.; Li, L.; Shi, Y.; Sozzi, W.J.; Zouhair, A.; Mirimanoff, R.O.; Azria, D. CD4 and CD8 T-lymphocyte apoptosis can predict radiation-induced late toxicity: A prospective study in 399 patients. Clin. Cancer Res. 2005, 11, 7426-7433. [CrossRef] [PubMed]

34. Tamura, T.; Ishihara, M.; Lamphier, M.S.; Tanaka, N.; Oishi, I.; Aizawa, S.; Matsuyama, T.; Mak, T.W.; Taki, S.; Taniguchi, T. An IRF-1-dependent pathway of DNA damage-induced apoptosis in mitogen-activated T lymphocytes. Nature 1995, 376, 596-599. [CrossRef]

35. El Jamal, S.M.; Taylor, E.B.; Abd Elmageed, Z.Y.; Alamodi, A.A.; Selimovic, D.; Alkhateeb, A.; Hannig, M.; Hassan, S.Y.; Santourlidis, S.; Friedlander, P.L.; et al. Interferon gamma-induced apoptosis of head and neck squamous cell carcinoma is connected to indoleamine-2,3-dioxygenase via mitochondrial and ER stress-associated pathways. Cell Div. 2016, 11, 11. [CrossRef]

36. Brzostek-Racine, S.; Gordon, C.; Van Scoy, S.; Reich, N.C. The DNA damage response induces IFN. J. Immunol. 2011, 187, 5336-5345. [CrossRef]

37. Kim, M.K.; Song, J.Y.; Koh, D.I.; Kim, J.Y.; Hatano, M.; Jeon, B.N.; Kim, M.Y.; Cho, S.Y.; Kim, K.S.; Hur, M.W. Reciprocal negative regulation between the tumor suppressor protein p53 and B cell CLL/lymphoma 6 (BCL6) via control of caspase-1 expression. J. Biol. Chem. 2019, 294, 299-313. [CrossRef]

38. Youlyouz-Marfak, I.; Gachard, N.; Le Clorennec, C.; Najjar, I.; Baran-Marszak, F.; Reminieras, L.; May, E.; Bornkamm, G.W.; Fagard, R.; Feuillard, J. Identification of a novel p53-dependent activation pathway of STAT1 by antitumour genotoxic agents. Cell Death Differ. 2008, 15, 376-385. [CrossRef]

39. Chapgier, A.; Kong, X.F.; Boisson-Dupuis, S.; Jouanguy, E.; Averbuch, D.; Feinberg, J.; Zhang, S.Y.; Bustamante, J.; Vogt, G.; Lejeune, J.; et al. A partial form of recessive STAT1 deficiency in humans. J. Clin. Invest. 2009, 119, 1502-1514.

40. Villarino, A.V.; Kanno, Y.; Ferdinand, J.R.; O'Shea, J.J. Mechanisms of Jak/STAT signaling in immunity and disease. J. Immunol. 2015, 194, 21-27. [CrossRef]

41. Kernbauer, E.; Maier, V.; Stoiber, D.; Strobl, B.; Schneckenleithner, C.; Sexl, V.; Reichart, U.; Reizis, B.; Kalinke, U.; Jamieson, A.; Müller, M.; Decker, T. Conditional Stat1 ablation reveals the importance of interferon signaling for immunity to Listeria monocytogenes infection. PLoS Pathog. 2012, 8, e1002763. [CrossRef] [PubMed]

42. Chen, J.; Zhao, J.; Chen, L.; Dong, N.; Ying, Z.; Cai, Z.; Ji, D.; Zhang, Y.; Dong, L.; Li, Y.; et al. STAT1 modification improves therapeutic effects of interferons on lung cancer cells. J. Transl. Med. 2015, 13, 293. [CrossRef] [PubMed]

43. Muñoz-Fontela, C.; Mandinova, A.; Aaronson, S.A.; Lee, S.W. Emerging roles of p53 and other tumour-suppressor genes in immune regulation. Nat. Rev. Immunol. 2016, 16, 741-750. [CrossRef] [PubMed]

44. Saha, B.; Jyothi Prasanna, S.; Chandrasekar, B.; Nandi, D.C. Gene modulation and immunoregulatory roles of interferon gamma. Cytokine 2010, 50, 1-14. [CrossRef] [PubMed]

45. Zenke, K.; Muroi, M.; Tanamoto, K.I. IRF1 supports DNA binding of STAT1 by promoting its phosphorylation. Immunol. Cell. Biol. 2018, 96, 1095-1103. [CrossRef] [PubMed]

46. He, H.; Sun, Y. Ribosomal protein S27L is a direct p53 target that regulates apoptosis. Oncogene 2007, 26, 2707-2716. [CrossRef] [PubMed]

47. Park, W.R.; Nakamura, Y. p53CSV, a novel p53-inducible gene involved in the p53-dependent cell-survival pathway. Cancer Res. 2005, 65, 1197-1206. [CrossRef] [PubMed]

48. Andrysik, Z.; Kim, J.; Tan, A.C.; Espinosa, J.M. A genetic screen identifies TCF3/E2A and TRIAP1 as pathway-specific regulators of the cellular response to p53 activation. Cell Rep. 2013, 3, 1346-1354. [CrossRef] [PubMed]

49. Moreno-Villanueva, M.; Wu, H. Radiation and microgravity - Associated stress factors and carcinogenesis. REACH 2019, 13, 100027. [CrossRef]

50. Cekanaviciute, E.; Rosi, S.; Costes, S.V. Central Nervous System Responses to Simulated Galactic Cosmic Rays. Int. J. Mol. Sci. 2018, 19, 3669. [CrossRef]

51. Kabacik, M.G.; Raffy, C.; Bouffler, S.; Badie, C. Time, dose and ataxia telangiectasia mutated (ATM) status dependency of coding and noncoding RNA expression after ionizing radiation exposure. Radiat. Res. 2015, 183, 325-337. [CrossRef] 
52. Rràs-Fresneda, M.; Barquinero, J.F.; Gomolka, M.; Hornhardt, S.; Rössler, U.; Armengol, G.; Barrios, L. Differences in DNA Repair Capacity, Cell Death and Transcriptional Response after Irradiation between a Radiosensitive and a Radioresistant Cell Line. Sci. Rep. 2016, 6, 27043. [CrossRef]

53. Chen, J.; Cheung, F.; Shi, R.; Zhou, H.; Lu, W.; CHI Consortium. PBMC fixation and processing for Chromium single-cell RNA sequencing. J. Transl. Med. 2018, 16, 198. [CrossRef]

54. Dobin, A.; Davis, C.A.; Schlesinger, F.; Drenkow, J.; Zaleski, C.; Jha, S.; Batut, P.; Chaisson, M.; Gingeras, T.R. STAR: Ultrafast universal RNA-seq aligner. Bioinformatics 2013, 29, 15-21. [CrossRef]

55. Van der Maaten, L. Accelerating t-SNE using Tree-Based Algorithms. J. Mach. Learn. Res. 2018, 15, 3221-3245.

56. Yu, D.; Huber, W.; Vitek, O. Shrinkage estimation of dispersion in Negative Binomial models for RNA-seq experiments with small sample size. Bioinformatics 2013, 29, 1275-1282. [CrossRef]

57. Famoye, F. A new bivariate generalized Poisson distribution. Stat. Neerl. 2010, 64, 112-124. [CrossRef]

(C) 2019 by the authors. Licensee MDPI, Basel, Switzerland. This article is an open access article distributed under the terms and conditions of the Creative Commons Attribution (CC BY) license (http://creativecommons.org/licenses/by/4.0/). 